\title{
CONTEXTO HISTÓRICO, ECONÔMICO E POLÍTICO DA ENGENHARIA NO BRASIL: DO SÉCULO XVIII AO SÉCULO XXI
}

\author{
Adriana Maria Tonini ${ }^{1}$
}

\section{RESUMO}

No Brasil e no mundo, o progresso tecnológico e o crescimento econômico de um país dependem da formação em engenharia. Nesse sentido, justifica-se a necessidade de investigações que alinhavem algumas interações entre essa área profissional e as políticas educacionais do ensino superior, em especial, dos cursos de engenharia. Assim, este artigo tem por objetivo apresentar o contexto histórico, econômico e político do curso de Engenharia, tentando explicar como este sempre esteve relacionado ao sistema de produção econômica do país e ao desenvolvimento geoeconômico e político que vem simultaneamente atrelado a novas perspectivas de formação nessa área.

Palavras-chave: Formação; engenharia; tecnologia; políticas públicas.

\section{HISTORICAL, ECONOMIC AND POLITICAL CONTEXT OF ENGINEERING IN BRAZIL: FROM THE 18th CENTURY TO THE 21st CENTURY}

\begin{abstract}
In Brazil and in the world, the technological progress and the economic growth of a country depend on training in engineering. This justifies the need of some investigations to promote professional interactions between this area and the educational policies of higher education, in particular, of engineering degrees. Thus, this article aims to present the historical, economic and political context of the Engineering course, trying to explain how it has always been related to the economic system output of the country, and also to the geoeconomic and political development which is simultaneously coupled to new vistas of training in this area.
\end{abstract}

Keywords: Formation; engineering; technology; public politics. 


\section{INTRODUÇÃO}

Este artigo tem por objetivo apresentar o contexto histórico, econômico e político do curso de Engenharia, no Brasil, tentando explicar como esse curso sempre esteve relacionado ao sistema de produção econômica do país e ao desenvolvimento geoeconômico e político que vem, simultaneamente, atrelado às novas perspectivas de formação nessa área.

Os primeiros relatos sobre a história local da engenharia remetem à época do Brasil Colônia, quando, em 1792, Dona Maria I, rainha de Portugal, mandou construir, no Rio de Janeiro, uma Academia Real de Fortificação, Artilharia e Desenho, seguindo os moldes da mesma escola existente em Portugal. ${ }^{1}$ Essa escola tinha como objetivo formar soldados técnicos na arte da construção de fortificações para promover a defesa da Colônia contra os ataques e invasões de outras nações.

A primeira escola de engenharia propriamente dita, a Academia Real Militar, foi criada em 23 de abril de 1811, pelo rei D. João VI, em substituição à Real Academia de Artilharia, Fortificações e Desenho. Essa escola passou por diversas denominações: em 1822, depois da Independência, teve seu nome mudado para Academia Imperial Militar; em 1832, para Academia Militar da Corte; em 1840, para Escola Militar e, a partir de 1858, passou a denominar-se Escola Central.

A partir do século XVIII, foram criadas as duas primeiras escolas brasileiras de engenharia para civis. Em abril de 1874, foi inaugurada a Escola Politécnica do Rio de Janeiro, em substituição a Escola Central, e, logo a seguir, em 12 de outubro de 1876, a Escola de Minas de Ouro Preto. Pouco tempo depois, cinco outras escolas de engenharia foram inauguradas no país: em 1893, a Politécnica de São Paulo, a Politécnica do Mackenzie College e a Escola de Engenharia do Recife; em 1897, a Politécnica da Bahia e a Escola de Engenharia de Porto Alegre.

\footnotetext{
Ver $<$ http://pt.wikipedia.org/wiki/Instituto_Militar_de Engenharia $>$. Acesso em 06 ago. 2006.
}

No início do século XIX, o exército brasileiro, sob influência da Alemanha, eliminou a formação local de engenheiros militares, passando, então, a enviar os brasileiros a escolas no exterior. A falta de escolas de engenharia militar, de instrumentos e laboratórios escolares acarretou um deficit no desenvolvimento tecnológico do país.

Porém, em 1920, veio ao Brasil uma missão militar francesa que acabou por convencer os militares brasileiros de que o país não poderia ficar sem uma instituição de ensino militar superior, na área de engenharia, o que acabou por gerar a Escola de Engenharia Militar, fundada em 1932. Para Lessa (2002, p. 3) "nos campos políticos e profissionais dos dois grandes clubes Militar e de Engenharia é que o positivismo vai construir sua base mais firme no Brasil, neste período os grandes positivistas brasileiros ou eram instrutores da academia militar ou eram grandes engenheiros".

Entre a eliminação do curso de engenharia militar secular e sua reativação, houve imensos danos ao desenvolvimento intelectual, tecnológico e econômico do país, marcando o início do século XX. Nesse período, o Brasil ficou ainda mais dependente tecnologicamente das forças armadas externas, pois uma imensa parte de conhecimento fora perdida com a quebra na sequência de ensino, gerando o atraso ainda sentido na atualidade.

\section{O DESENVOLVIMENTO DA EDUCAÇÃO SUPERIOR NO BRASIL E A ENGENHARIA}

Iniciando com o contexto autoritário da República, com forte controle estatal, surge o Decreto $\mathrm{n}^{\circ}$ 19.851, de 11 de abril de 1931, assinado por Getúlio Vargas e Francisco Campos, instituindo o "Estatuto das Universidades Brasileiras" e indicando o modelo universitário que o ensino superior deveria seguir, bem como o formato geral para as universidades públicas brasileiras, que colocava a engenharia entre uma das cinco unidades da organização do sistema vigente nesse período, a saber, Direito, Medicina, 
Engenharia, Educação, Ciências e Letras (CAVALIERE, 1996).

As reformas do ensino superior brasileiro, na década de 1930, trouxeram contribuições importantes para a engenharia. A partir desse período, iniciaram-se as lutas para a profissionalização dos engenheiros, as quais foram se concretizando devido à boa aceitação das novas ideias de gestão da sociedade, visando à modernização (BARBOSA, 1993).

Com o início das lutas pela profissionalização, surge a necessidade de regulamentar as atribuições do engenheiro, ou seja, as atividades que o profissional de engenharia poderia exercer dentro de sua modalidade de formação, ficando as mesmas sujeitas à fiscalização por parte dos órgãos responsáveis. É dessa época a criação do primeiro instrumento legal específico, o Decreto $\mathrm{n}^{\mathrm{o}} 23.569$, de 11 de dezembro de 1933, que regulamentava as atribuições profissionais do exercício das profissões de engenheiro, arquiteto e agrimensor, instituindo como responsáveis pela coordenação e físcalização dessas atividades o Conselho Federal de Engenharia, Arquitetura e Agronomia (CONFEA) e os Conselhos Regionais de Engenharia Arquitetura e Agronomia (CREAs). Esse decreto não se encontra mais em vigor, porém, existem ainda muitos profissionais de engenharia enquadrados por ele. Em substituição a esse decreto, foi promulgada, em 24 de dezembro de 1966, a Lei $\mathrm{n}^{\circ}$ 5.194, do CONFEA, que fixa as atribuições profissionais e a fiscalização do exercício profissional de engenharia.

Ao tempo dessa normatização profissional do engenheiro, o país era marcado pela modernização econômica. Durante o Estado Novo (1937-1945), os objetivos no campo educacional, segundo Ghiraldelli (2006), eram criar e ordenar um sistema de ensino profissionalizante, porém, esse sistema não atendeu aos interesses imediatistas da industrialização crescente. Nesse sentido, o autor evidencia que o sistema público de ensino profissional não conseguiu fornecer a qualificação da mão-de-obra necessária ao parque industrial que se instalava no país.

Com o término da Segunda Grande Guerra, em 1945, o mundo experimentou um significativo avanço tecnológico, enquanto, no plano econômico, o crescimento industrial brasileiro era estimulado, segundo Vieira e Farias (2003, p. 105), "por restrições às importações e por um regime cambial desfavorável às exportações". O período pósguerra favoreceu investimentos educacionais na área de engenharia e, logo após o final da Segunda Guerra Mundial, o governo federal criou o Instituto Tecnológico da Aeronáutica (ITA). Fundado em 1947, "tinha como principal meta formar uma mão-de-obra altamente qualificada, com mercado de trabalho garantido no campo militar, na grande expansão da aviação comercial e na nascente indústria aeroespacial brasileira" (PESSOTTI, 2002). ${ }^{2}$

A década de 1950, conhecida como a década desenvolvimentista do governo JK (Juscelino Kubitschek), é marcada por dois períodos importantes da história, em que o crescimento econômico e a modernização do país são bastante visíveis. São eles: o segundo período do governo de Getúlio Vargas (19511954) e o período do governo de Juscelino Kubitschek (1956-1961). Ganham ascensão, nessa época, os cursos de engenharia, com a criação de diversos órgãos no setor industrial. Segundo Vieira e Farias (2003, p. 106), “com o objetivo de dar continuidade ao processo de industrialização iniciado no País, Getúlio Vargas desencadeia várias iniciativas nesse sentido": cria o Banco Nacional de Desenvolvimento Econômico (BNDE), em 20 de junho de 1952, a Petrobrás, em 3 de outubro de 1953, e a Eletrobrás, em 13 de janeiro de 1962.

Getúlio Vargas retornou à política apoiando-se no populismo, para conquistar adesão ao seu projeto nacionalista, o que não agradou aos segmentos políticos mais conservadores, perdendo credibilidade e sua susten-

\footnotetext{
Ver <http://www.klepsidra.net/>. Acesso em 30 mar. 2006.
} 
tação no governo. Diante da forte pressão para renunciar, em 1954, o presidente Vargas suicida-se, porém, seu governo contribuiu fortemente para alavancar a engenharia com a demanda verificada nos setores industriais e nas estatais por ele criadas para atender aos serviços básicos de exploração do petróleo e a geração de energia elétrica para a população áreas então decretadas como monopólio estatal.

O governo JK também foi bem propício para a engenharia. Com um discurso desenvolvimentista - "cinqüenta anos de progresso em cinco de governo" -, contribuiu para que, em seu mandato, surgissem, no Brasil, três cursos de engenharia por ano; ao final de seu governo, estavam em funcionamento 99 cursos de engenharia no país. $^{3}$

Privilegiando a indústria de base alimentação, energia, transporte e educação -, JK propõe um plano nacional de desenvolvimento - o Plano de Metas - e recorre ao capital estrangeiro para estimular investimentos no setor industrial, implantando a indústria automobilística, a de eletrodomésticos e ainda promovendo a realização de grandes empreendimentos, como estradas e usinas hidroelétricas.

Também nessa década, a criação do CNPq (Conselho Nacional de Pesquisa), em 1951, ligado ao governo federal, e com a meta de estimular as pesquisas de caráter científico e tecnológico no país, contribui para a valorização do engenheiro. A adoção ao modelo de ensino norte-americano, ocorrida então, em grande medida, se deve ao apoio do $\mathrm{CNPq}$ aos professores bolsistas que, ao retornarem às suas universidades de origem, provocaram novas orientações para o ensino de engenharia, que passou a valorizar a articulação do ensino e das práticas escolares com as atividades científicas, econômicas e industriais (ARANTES, 2002, p. 57).

A década de 1960 teve como marco sócio-histórico a implantação do regime

\footnotetext{
Ver $<$ http://www.inep.gov.br>. Acesso em 27 ago. 2006.
}

militar. Segundo Vieira e Farias, "as diferenças ideológicas entre tendências de direita e de esquerda é que constituíram a base sobre a qual se sustentou o golpe militar de 1964". No contexto da Guerra Fria, entre as grandes potências internacionais (Estados Unidos e União Soviética), os Estados Unidos apóiam o golpe militar no Brasil e na América Latina, "estimulando a radicalização do regime e oferecendo suporte financeiro necessário ao desenvolvimento de grandes projetos" (2003, p. 104 e 121).

No campo educacional, o governo militar sofreu grande pressão da United States Agency for International Development (USAID), órgão do governo dos EUA, presente no Brasil desde os anos de 1950, que criticava duramente o modelo brasileiro de Universidade, à exceção do ITA e da Universidade de Brasília (UnB), tanto que, em 1967, foi assinado um famoso acordo entre o MEC e a USAID, propondo reformas no ensino universitário do país, segundo o modelo norte-americano.

As bases da reforma de 1968 foram devidas, principalmente, à pressão da classe média, representada no movimento estudantil que, naquele momento, buscava se inteirar da vida política nacional. É interessante ressaltar que a União Nacional dos Estudantes (UNE), segundo Trindade (2004), a partir dos anos de 1960, assumiu uma bandeira de luta, por meio de greve pelo co-governo da universidade, despertando na sociedade uma tomada de “consciência nacional” a respeito da questão universitária. Tal movimento foi marcado pela reação direta e autoritária do regime militar, que via naquela juventude uma ameaça à ordem pública e até mesmo ao princípio da propriedade privada no país. O movimento estudantil da década de 60 não ocorreu somente no Brasil; em vários países se denunciava e se combatia, nesse período, o princípio da centralização, ou seja, o controle administrativo, técnico e ideológico exercido por governos de exceção. Apesar de ter sido interrompido pelo golpe militar de 1964, o movimento estudantil ressurgiu nas mobili- 
zações que marcaram o movimento de 1968, fazendo com que os militares entrassem diretamente no processo da reforma (TRINDADE, 2004).

Assim, a Lei $\mathrm{n}^{\mathrm{o}}$ 5.540/68, "Lei da Reforma Universitária", foi baseada nos estudos do Relatório Atcon (Rudolph Atcon, teórico norte-americano) e no Relatório Meira Matos (coronel da Escola Superior de Guerra), e teve como modelo a UnB, fundada em 1961 e idealizada pelo antropólogo Darcy Ribeiro, inspirada no modelo de Universidade dos EUA, com estrutura por departamentos e não mais por cátedras; campus único; autonomia didática, técnica e administrativa; e dirigida por colegiados, com maior democracia interna e uma perspectiva nacionalista e desenvolvimentista para a pesquisa (PESSOTTI, 2002). ${ }^{4}$ Todas essas mudanças ocorridas na organização do ensino superior a partir de 1968, com a reforma universitária, também se refletiram nas engenharias, registrando-se um recorde, nesse ano, com a criação de doze novos cursos no país.

De acordo com Vieira e Faria (2003), durante o regime militar, avançam os processos de urbanização e de industrialização. Com isso, cresce a demanda, por parte da classe média, por vagas nas universidades. Ainda segundo as autoras, a reforma universitária teve por finalidade oferecer resposta às demandas crescentes por ensino superior, e pretendia formar quadros desse nível para dar substância ao crescimento econômico gerado pelo que ficou conhecido como o "milagre econômico".

No período 1968-1973, o Brasil vivera o chamado milagre econômico, registrando altas taxas de crescimento, em função da ampla disponibilidade de recursos financeiros provenientes dos países desenvolvidos, mas essa estabilidade econômica é interrompida pela crise mundial do petróleo. No governo de Ernesto Geisel, foi lançado o Plano Nacional de Desenvolvimento, que intentava reajustar a economia, em face da escassez mundial de

\footnotetext{
$4 \quad$ Ver $<$ http://www.klepsidra.net/>. Acesso em 30 mar. 2006.
}

petróleo, acelerando-se o processo de substituição das importações, com ênfase nos bens de capital e na eletrônica pesada. No início da década de 1980, verificam-se a desaceleração do processo de crescimento econômico e a expansão de tendências inflacionárias, num quadro de distensão política que iria culminar na campanha das "Diretas Já", que exigia o retorno ao Estado democrático. ${ }^{5}$

Nessa fase, projetos de desenvolvimento de grande porte são concebidos e realizados, tais como Itaipu Binacional, Ponte RioNiterói, Rodovia Transamazônica, usinas nucleares, e o Brasil abre espaço na agenda das grandes economias mundiais.

Nessa etapa de desenvolvimento do país, a formação tecnicista e científica do engenheiro é de extrema relevância; daí esse período ser o de maior valorização da formação em engenharia, e os cursos adquirem o status dos melhores e a profissão passa a ser uma das mais bem remuneradas no mercado nacional.

Segundo Kawamura (1979), os engenheiros e demais técnicos de nível superior, nesse contexto, passaram a ocupar cargos técnicos no processo de produção. A presença de órgãos e técnicos estrangeiros, com significativa participação de engenheiros na definição de políticas culturais, bem como a importação de abordagens metodológicas pragmáticas do exterior para a questão cultural brasileira contribuiu, a partir de 1968, para o desenvolvimento do caráter tecnicista da educação.

Também numa visão retrospectiva, ao analisar o período do regime militar, entre 1964 e 1985, Peixoto (1998) demonstra que os governos militares envidaram esforços no sentido de elaborar uma política de ciência e tecnologia, com o objetivo de inserir o país entre as potências mundiais, investindo na formação de pesquisadores, através de programas de pós-graduação. Assim, mais uma vez, justifica-se a valorização da enge-

\footnotetext{
Ver <http://www.bb.com.br/>. Acesso em 30 mar. 2006
} 
nharia ocorrida nesse período da história socioeconômica e política do Brasil.

De acordo com Arantes (2002), para garantir certa qualidade na formação do profissional em engenharia, além de um mínimo de equivalência entre cursos da mesma natureza, o Conselho Federal de Educação, hoje substituído pelo Conselho Nacional de Educação, aprovou, através da Resolução no 48/76, os currículos mínimos de conteúdos e de duração para as engenharias, que constituíram a base dos currículos existentes no país, até a aprovação da Lei de Diretrizes e Bases da Educação, a LDB $n^{\circ}$ 9.394/96, que revoga a legislação anterior sobre a reforma universitária (Lei $\mathrm{n}^{\circ}$ 5.540/68).

Por sua vez, a década de 1980 não apresentou grande crescimento desses cursos, registrando uma média de apenas cinco novos cursos criados por ano; foi a década considerada como a "década perdida", com altas taxas de inflação, crise fiscal e crescimento da dívida pública, causando estagnação no desenvolvimento do país, o que refletiu diretamente no baixo índice de criação de novos cursos de engenharia (OLIVEIRA, 2005).

Com base no crescimento do ensino superior registrado na década anterior é que, nos anos 80 , ocorreram inúmeras tentativas de se implantar novas reformas no Brasil. Segundo Pessotti (2002), ${ }^{6}$ algumas propostas sempre estiveram presentes nesse período: os currículos mínimos, que permitiriam à Universidade adaptar-se à sua realidade e ao mercado de trabalho; a complementação orçamentária, a partir do financiamento originado do setor privado; a extinção do princípio da universalidade; e a racionalização dos recursos.

A década de 1990 é marcada, assim, por um discurso de racionalização dos recursos, autonomia e avaliação institucional, tanto que os governos de Fernando Collor de Mello (15/03/1990-29/12/1992), Itamar Franco (29/12/1992-01/01/1995) e Fernando Henrique Cardoso (01/01/1995-01/01/2003) transforma-

\footnotetext{
6 Ver $<$ http://www.klepsidra.net/>. Acesso em 30 mar. 2006.
}

ram e massificaram ainda mais a educação superior brasileira, criando novas exigências e modelos também para as universidades públicas (PESSOTTI, 2002). ${ }^{7}$

Para Cunha (2003), a proposta para a educação superior, no mandato $\mathrm{FHC}$, afirmava a necessidade de se estabelecer uma "verdadeira parceria" entre setor privado e governo, entre universidade e indústria, tanto na gestão quanto no financiamento do sistema brasileiro de desenvolvimento científico e tecnológico, atuando no sistema educacional pelo topo, isto é, pela Universidade, entendendo-se que a competência científica e tecnológica é fundamental para garantir a qualidade do ensino básico, secundário $\mathrm{e}$ técnico, assim como aumentar a qualificação geral da população. Com esse discurso científico e tecnológico, surgiam no país mais cursos de engenharia no setor privado.

Assim, é nesse cenário de governo que, em 1996, foi aprovada a Lei de Diretrizes e Bases da Educação Nacional (LDB, $\mathrm{n}^{\circ}$ 9.394/96), uma lei que já vinha sendo debatida desde a promulgação da Constituição Federal de 1988, e que esteve na pauta de discussões de vários eventos científicos de educação, principalmente na Associação Nacional de Pós-Graduação e Pesquisa em Educação (ANPEd) e no Sindicato Nacional dos Docentes das Instituições de Ensino Superior (ANDES), antes mesmo de sua aprovação.

A aprovação da Lei $n^{0}$ 9.394/1996, trouxe como consequência a revogação da Resolução $n^{\text {o }} 48 / 76,{ }^{8}$ que estabelecia o currículo mínimo dos cursos de engenharia, bem como das exigências das denominações e modalidades e suas habilitações (resoluções $n^{\circ}$ 50/76) das políticas educacionais para engenharia.

Porém, a amplitude e o conteúdo de normalização do ensino superior, pela Lei de Diretrizes e Bases da Educação Nacional, de

\footnotetext{
Documento disponível na internet: em $<$ http://www.klepsidra. net/>. Acesso em 30 mar. 2006.

8 Resolução 48/76, de abril de 1976, do Conselho Federal de Educação (CFE), que disciplinava os currículos mínimos para a graduação em engenharia.
} 
20 de dezembro de 1996, requerem observações e determinações para um melhor entendimento, daí a necessidade de normalizações fragmentadas para o detalhamento dos novos moldes da reforma universitária e, por extensão, para os cursos de engenharia que se encontravam regulamentados pela Resolução $n^{\circ}$ 48/76, de abril de 1976, do Conselho Federal de Educação (CFE). Assume-se, como expõe Pinto (2003):

Em seu artigo 48 a LDB desvincula o diploma do exercício profissional, ao estabelecer que o diploma de cursos superiores tem validade como prova de formação recebida. Este aspecto é importante para os cursos de Engenharia, pois permite uma flexibilidade maior nos currículos, visto serem agora independentes do exercício profissional. As escolas de graduação em engenharia devem se preocupar com a formação a imprimir a seus egressos e as instituições profissionais, por sua vez, com as atribuições profissionais.

Assim, publicado no Diário Oficial da União de 25/02/2002, Seção 1, p. 17, o parecer CNE/CES n ${ }^{\circ}$ 1.362/2001 (homologado por Despacho do Ministro em 22/02/2002), que estabelece, através da Resolução CNE/CES n ${ }^{\circ}$ 11, de 11 de março de 2002, as Diretrizes Curriculares Nacionais do Curso de Graduação em Engenharia, traz contribuições pertinentes e relevantes para a formação do engenheiro.

As Diretrizes Curriculares Nacionais para a Engenharia (DCN) contribuíram para o aumento no número de cursos, modalidades e ênfases de engenharia no país. E constata-se que o principal motivo desse aumento é a flexibilização dada pelas DCN. Observa-se, também, com o advento das Diretrizes, a predominância da abertura de novos cursos pelo setor privado de educação.

A educação superior, no governo de Luiz Inácio Lula da Silva (2002/2010), traz a reforma universitária como agenda de prioridade. Em 2003, dando continuidade às medidas de avaliação do país, o MEC criou a Comissão Especial de Avaliação, que elaborou a proposta do Sistema Nacional de Avaliação da Educação Superior (SINAES), aprovado pelo Congresso, por intermédio da Lei $\mathrm{n}^{\circ}$ 10.861, de 14 de abril de 2004, no sentido de que os processos de avaliação e regulação dos cursos e instituições de ensino superior caminhem na direção de uma melhoria na qualidade da educação.

Dando sequência ao processo de reforma da educação superior, em 8 de junho de 2006, o presidente da República encaminhou ao Congresso Nacional o projeto da reforma universitária, em que se assegura a autonomia das universidades, garantindo ainda o repasse de $75 \%$ do orçamento do MEC ao ensino superior, durante dez anos, e estabelecendo critérios de qualidade na distribuição de recursos.

A principal ideia dessa reforma é consubstanciar um marco regulatório para toda a educação superior nacional, o que implica a manutenção, pelo Ministério da Educação, da responsabilidade de pré-credenciamento, credenciamento, renovação de credenciamento, alteração de classificação de instituições de ensino, autorização, reconhecimento e renovação de reconhecimento de cursos. ${ }^{9}$

Essas mudanças na educação superior, no Brasil, trarão repercussões importantes na engenharia nacional, pois o projeto tem como um dos seus objetivos centrais criar condições para a expansão do ensino superior, com qualidade e equidade, com a efetiva democratização do acesso ao ensino superior.

Diante desse quadro, Genro (2005, p. 4) afirma que, nos dias de hoje, o grande desafio é a construção de um sistema de educação superior que realize o equilíbrio entre qualidade acadêmica e compromisso social. Portanto, a legislação em que provavelmente desembocará a nova reforma será a primeira a ser construída num período democrático, o que pressupõe amplo debate com os segmentos representativos da comunidade universitária e da sociedade. A reforma é, portanto, de suma importância para romper, possivelmente, com

9 Ver $<$ http://www.mec.gov.br/reforma/Noticias_Detalhe.asp/ Codigo $=8214>$. Acesso em 15 jul. 2006. 
a histórica dependência científica, tecnológica e cultural do Brasil.

$\mathrm{O}$ rompimento com a dependência científica e tecnológica do Brasil, prevista na reforma atual do ensino superior, buscará privilegiar a formação em engenharia e um novo profissional da área será necessário para atender à demanda do mundo do trabalho, e esses novos profissionais devem ter uma formação que contemple o novo perfil do engenheiro, com visão crítica, humana, social, reflexiva, generalista e tecnológica, conforme propõem as novas Diretrizes Curriculares Nacionais de Engenharia, publicada em 2002.

\section{CONCLUSÕES}

Ao analisar o contexto histórico, econômico e político da engenharia, como apresentado neste artigo, fica clara a valorização da engenharia ocorrida principalmente no período do regime militar (19641984), quando é instaurado, no Brasil, o desenvolvimento de uma política de ciência e tecnologia, a partir de 1973.

Nesse período, segundo o primeiro Plano Nacional de Desenvolvimento (1972-74) e o Plano Básico de Desenvolvimento Científico e Tecnológico (1973-74), a revolução tecnológica, principalmente nas últimas décadas, repercute profundamente sobre o desenvolvimento industrial e o comércio internacional, passando o crescimento econômico a ser cada vez mais determinado pelo progresso tecnológico, e esse progresso inclui e depende da formação em engenharia: "tudo o que aconteceu no País durante esse período teve a assinatura do engenheiro, quer na concepção, quer na execução" (LESSA, 2002, p. 8).

Após o regime militar, já na década de 1990, ocorreram ciclos de expansão do ensino, porém com maior participação no mercado do setor privado, que estava em condições de oferecer mais cursos para atender à demanda, devido às políticas educacionais implantadas pelos governos desse período, que buscavam a contenção de gastos públicos e a expansão do referido setor privado, cumprindo as definições do Fundo Monetário Internacional.
Merece destaque, nesse sentido, o período do governo de Fernando Henrique Cardoso (1995-2003). Adotando políticas e reformas educacionais fundadas nos imperativos financeiros e parcerias com o setor privado, visou à redução de gastos públicos com a educação e com a implementação de processos de regulação, gestão e formatos de privatização, favorecendo a abertura de instituições privadas de ensino superior e, consequentemente, de mais cursos de engenharia nessas IES. Assim, de 525 cursos de engenharia, em 1995, chegamos a alcançar 1.304, em 2005, com uma expansão de 77\%, no setor particular, e $240 \%$, no setor público.

Concluindo a apresentação desse contexto, que abarca até o período do governo Lula (2003-2011), observa-se que as propostas de reforma do ensino superior constituem uma das prioridades do Ministério da Educação, enfatizando a expansão com qualidade acadêmica e a democratização do acesso da sociedade ao ensino universitário, incluindo maior propagação também das escolas públicas de nível superior.

Espera-se, neste artigo, ter desenvolvido o histórico do curso de engenharia, bem como ter alinhavado algumas interações entre essa área profissional e as políticas educacionais do ensino superior inseridas no contexto social brasileiro.

\section{REFERÊNCIAS}

ARANTES, Eduardo Marques. Reengenharia do ensino das engenharias: da construção do discurso oficial à produção de reformas curriculares. Tese (Doutorado em Educação) - Faculdade de Educação, Universidade Federal de Minas Gerais, Belo Horizonte, 2002.

BARBOSA, Maria Ligia de Oliveira. Reconstruindo as Minas e planejando as Gerais: os engenheiros e a constituição dos grupos sociais. Tese (Doutorado em Ciências Sociais) - Instituto de Filosofia e Ciências Humanas da UNICAMP, Campinas, 1993.

BRASIL. Decreto Federal n. 23.569, de 11 de dezembro de 1933. Regula o exercício das profissões de engenheiro, de arquiteto e de agrimensor. Brasília/DF, 1933.

BRASIL. Lei n. 5.194, de 24 de dezembro de 1966. Regula o exercício das profissões de 
engenheiro, de arquiteto e de engenheiroagrônomo, e dá outras providências. Brasília/DF, 1966.

BRASIL. Lei n. 5.540, de 28 de novembro de 1968. Fixa normas de organização e funcionamento do ensino superior e sua articulação com a escola media, e dá outras providencias. Brasília/DF, 1968.

BRASIL. Lei n. 9.394, de 20 de dezembro de 1996. Estabelece as diretrizes e bases da educação nacional. Brasília/DF, 1996.

BRASIL. Lei n. 10.861, de 14 de abril de 2004. Institui o Sistema Nacional de Avaliação da Educação Superior - SINAES e dá outras providências. Brasília/DF, 2004.

BRASIL. CONSELHO FEDERAL DE EDUCAÇÃO. Resolução n. 48, de 27 de abril de 1976. Fixa os mínimos de conteúdo e de duração do Curso de Graduação em Engenharia. Brasília/DF, 1976.

BRASIL. CONSELHO NACIONAL DE EDUCAÇÃO. Parecer CNE/CES n. 1362/2001, aprovado em 12 de dezembro de 2001. Assunto: Diretrizes Curriculares Nacionais dos Cursos de Engenharia. Diário Oficial da União. Brasília/DF, 25 de fevereiro de 2002. Seção 1, p. 17.

BRASIL. CONSELHO NACIONAL DE EDUCAÇÃO. Resolução CNE/CES n. 11/2002, aprovado em 11 de março de 2002. Institui as Diretrizes Curriculares Nacionais do Curso de Graduação em Engenharia. Diário Oficial da União. Brasília/DF, 9 de abril de 2002. Seção 1, p. 32.

CAVALIERE, Ana Maria Villela. Escola de educação integral: em direção a uma educação escolar multidimensional. Tese (Doutorado em Educação) - Faculdade de Educação da UFRJ, Rio de Janeiro, 1996.

CUNHA, Luiz Antônio. O ensino superior no octênio FHC. Revista Educação e Sociedade, Campinas: v. 24, n. 82, p. 37-61, abr. 2003.

GASPARIN, João Luiz; FAUSTINO, Rosângela Célia. A influência do positivismo e do historicismo na educação e no ensino de história.
Acta Scientiarum, Maringá, v. 23, n. 1, p. 157-166, 2001.

GENRO, Tarso. Anteprojeto da Reforma do Ensino Superior. Brasília/DF, 2005. Documento disponível na Internet: $<$ http://www.mec.gov.br/reforma $>$. Acesso em 10 jun. 2006.

GHIRALDELLI JR., Paulo. História da educação brasileira. São Paulo: Cortez, 2006.

KAWAMURA, Lili Katsuco. Engenheiro: trabalho e ideologia. São Paulo: Ática, 1979.

LESSA, Carlos. Conferência no VIII Encontro de Educação em Engenharia. Simpósio Engenharia, Universidade e Nação. Universidade Federal do Rio de Janeiro - UFRJ. Rio de Janeiro, nov. 2002.

OLIVEIRA, Vanderli Fava. Crescimento, evolução e o futuro dos cursos de engenharia. ABENGE. Revista de Ensino de Engenharia, v. 24, n. 2, p. 312, 2005 - ISSN 0101-5001.

PEIXOTO, Maria do Carmo de Lacerda. Política de ciência e tecnologia e formação do pesquisador. Cadernos de Sociologia, Porto Alegre, Programa de Pós-Graduação em Sociologia - UFRGS, v. 8, p. 45-67, dez. 1998.

PESSOTTI, Gabriel. USP, FFLCH e o estado de São Paulo. Revista Klepsidra. Curso de História da USP. out./nov., São Paulo, v. 13, 2002. Documento disponível na Internet: $<$ http://www.klepsidra.net/>. Acesso em 30 mar. 2006.

PINTO, Danilo Pereira; PORTELA, Júlio César da Silva; SOUZA, Antônio Claudio Gomes de. Lei de Diretrizes e Bases da Educação e Diretrizes Curriculares Nacionais. Revista Engevista, Niterói, v. 5, n. 9, p. 5-19, 2003.

TRINDADE, Helgio. República em tempos de reforma universitária: o desafio do governo Lula. Educação e Sociedade, Campinas, v. 25, n. 88, p. 819-44, out. 2004.

VIEIRA, Sofia Lerche; FARIAS Isabel Maria Sabino de. Política educacional no Brasil: introdução histórica. Brasília/DF: Editora Plano, 2003.

\section{DADOS DA AUTORA}

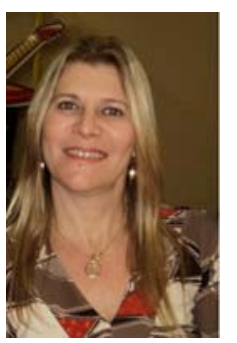

ADRIANA MARIA TONINI, doutora em educação pela Universidade Federal de Minas Gerais (UFMG) e engenheira civil pela UFMG, é professora adjunta da Universidade Federal de Ouro Preto (UFOP) e do Mestrado em Educação Tecnológica do CEFET-MG. Membro efetivo da comissão técnica de Ensino de Engenharia da Sociedade Mineira dos Engenheiros - SME/MG e associada da Associação Brasileira de Ensino de Engenharia - ABENGE. 